\title{
Parallel Computation in Correspondence and Signal Processing
}

\author{
G.Kavitha, N.Priya, R.Velvizhi, A.V.Allin Geo
}

\begin{abstract}
The calculation that is effective of $h$ as increased the computation accelerate of several systems. This paper summarize several of the most work that is essential the industry of interaction and sign processing making use of GPU.
\end{abstract}

Keywords: FFT, GPU, synchronous processing, LTE, soft ware define radio.

\section{INTRODUCTION}

Parallel process ing is among the areas which includes gotten attention that is excellent numerous res earchers all over the world into the las $\mathrm{t} 2$ decades. As an example of the res which are at the beginning of this fie ld of s tudy may be the work that's been carried out by Sung et al in 1992[1]. They has implemented time that is real italfilte ring in aparallel fashion. Their inbound information ended up being divided into mu ltip bloc that is le. Each block had been proces s ed s eparately from others us ing a s procedure that is Single. The primary objective of the parallelizing s cheme ended up being to increas e the procedure rate that is ing. Both types of electronic filters (Finite Impuls age Res pons e (FIR) and Infinite Impuls age Res pons e (IIR)) were imp le mented in their work [1] while the paper dis cussed above is an illustration associated with the early works in parallel process that is sys tem and its own application in d igital $s$ ignal processing, however the genuine work s tarted within the last decade as a result of progress that is made in dig ital co mputers . The applying that is primary ofparalle 1 proces $\mathrm{s}$ ing are electronic s ignal procedure ing in communicat ion and as tronomica 1 application and biome $\mathrm{d}$ ical image and $\mathrm{s}$ ignalproces $\mathrm{s}$ ing. The next $\mathrm{s}$ ection is certainly going to $\mathrm{s}$ ummarize some of the res earch in the field of communication and s procedure ing that is Signal.

\section{MATERIALS AND METHODOLOGY}

Although the paralle application that is 1 trategy was indeed utilized in s ignalproces s ing in the late for the twentieth century nevertheless the genuine and mos $t$ interes ting works have $\mathrm{s}$ tart ed after the great progress o fparalle $1 \mathrm{co}$ mputation in the las $t$ ten years and listed here are $\mathrm{s}$ ome regarding the res earches recently.

In 2007, Anwar and Sung implemented 16 taps FIR and IIR filters us GT that is ing X Graphics Process ing product (GPU). The GPU- basedimple model that is mented contrasted with another model which is imp le mented us ing Central Proces s ing Unit (CPU). The res ults s howed that there clearly was a s peed up calculation of 3 and 40 for IIR and FIR res pectively. They suggest the age that is us of ientutilizat ion of memory hierarchy for future work of recursive filters [2].
During 2009, Franco et al le that is imp a two dimensional (2- D) fas $t$ wavelet trans form us ing GPU. For the $\mathrm{s}$ imulat ion purpos age, they us eda Compute Un ified unit Architecture (CUDA-based) GPU card fro mNvidia [3]. The s peed of themodel is 21 times faster than the Central Processing Unit -bas ed type of the 2- D revolution let trans form. They verified the GPU model to check on its performance us ing 2048*2048, 4096*4096, and $8192 * 8192$ image $\mathrm{s}$ ize. This sort of model is really usefulwhenever there is a huge a mount of information to be processedespecially in medica 1 image and bio med ical s ignalproces $\mathrm{s}[3]$ that is ing. Trebienpresented the firs $t$ GPU-basedimple mentation model of a recurs linear dig ital filter that is ive. Their model had been contrasted with its Central Processing Unit that is equivalent-bas model. The comparis on res ults s howed that the GPU-based model provides a s peed up of 2 to 4 times in comparison with Central Processing Unit -bas ed one [4]. Wu et al us ed the co that is effective regarding the GPU within the imple mentation of a communication $s$ ys tem [5]. They implemented a TrellisMultip le Input numerous Output (MIMO) detector us ing s ingle floating point GPU. The implemented s ys tem is quite flexib le as co mpared $w$ ith Field Program Gate Array (FPGA )-bas ed one. The GPU -based s ys tem provides us a opportunity that is very good MIMO s oftware defined radio.

In 2010, Nylanden et al us ed GPUs to build a $2 * 2 \mathrm{MIMO}-$ Orthogonal Frequency M Access that is ultiple( detector. The detecto $\mathrm{r}$ ended up being implemented us ing two methods being various. The first one had been Selective Spanning with Fas t Enumerat ion (SSFE). The s one that's econd Layard Orthogonal Lattice Detector (LORD). The le that is imp was des igned to s atisfy the ma ximu $\mathrm{m}$ throughput but with cons ideration for the utilization associated with GPU res ources [6]. Bas ed on the paper, we can s ay that the GPU -based s ys tem is the next pro mising strategy for Long Term Evolution (LT E) imp le mentation and s oftware define radio. Previous s tudies encouraged Vieira to build a s le that is imp E receiver us ing GPU. He simulated their model in Matlab, C, and CUDA. He dis covered that the rate regarding the CUDA rule is faster than the s erial $\mathrm{C}$ rule but it is s $\mathrm{t}$ ill s lower than the Matlab rule [7].According to him, as a result of the s numbe that is shopping center of antennas the $\mathrm{s}$ peed regarding the $\mathrm{s}$ imulation was les $s$ than the Matlab one. The CUDA simulation will be faster than the Matlab one in the event that information ended up being increased by us ing a lot more than 40 antennas. 


\section{RESULTS AND DISCUSSION}

Last year, van der Veldt has generated a polyphas age filter us ingGPU and Intel i-core that is mult s ors. The implemented models were us ed for procedure inga amount that is huge of in astronomical applications. The res ults have actually showed that the GPU-based imp mentation that is le gives a better performance in term of s peed and power efficiency [8]. Bes ides van der Veldt, Mc Curry has implemented a polyphas age filter banking institutions to transform input that is outside ignal to channelized frequency s tream [9]. Bas ed on their res ults GPU will be a very promising device in genuine $t$ ime $d s$ that are igitalprocedure ing of radio as tronomy. Par and Tos un have presented a way to model particfilte that is le bas ed localization us ing GPU and mult i-core proces s ors [10]. The s peed us ing the synchronous s imulation is mostly about 75 times the s peed of the s equential model up they've accomplished. Their paper has concentrated greatly in the $\mathrm{s}$ peed up point $t$ that is born its part in enhancing the s peed in Advanced Driving As s is tance System (ADAS). They've recommended the investigation in other ADAS tasks s uch as vis ion and information which can be LIDAR ing which can be procedure ed s imultaneously. Su et al have presented a fresh means of imp le deblocking that is menting based in the GPU. The deblocking filters are a very technique that is popular movie compres $\mathrm{s}$ ion. Ergo increasing the calculation $\mathrm{s}$ peed of thes age filters will $\mathrm{g}$ ive us an extremely modification that is big the compres $s$ ion time for video clip coding [11]. Laguna -Sanchez et al have implemented the firs $\mathrm{t}$ OFDM over energy line communicat ion system us ing GPU [12]. According to the writers, their firs timple model that is mented a 12 times faster performance as contrasted with the CPU-bas ed one. They will have sugges $t$ the us age with this model as a that is firs tep in s imulating more advanced level interaction $s$ ys tems .[13]

In 2012, Do mene et al have actually des igned, s imulated, and implemented a Tomlins on - Harashima s that are precoding tem bas ed on GPU. Their model has gave a s peed of about 5.5 times the s peed of Central Processing Unit -bas ed imp le model that is mented. In contemporary communication s ys tems, there are many documents which have us ed the co that is effective for the GPUs. Sui et al have s imulated a Minimu $\mathrm{m}$ Mean Square Error (MM SE) MIMO OFDM detector us ing CUDA and GPU. [14]. The detector s pecifications have actually been s elected bas ed on the LT E s pecification. [15].The res ults have actually offered a tremendously high rate as contrasted with conventional s equential models [16] as other documents. $\mathrm{Wu}$ et al have us ed GPU to create s oft MIMO detector combined with channel decoder to have the bes $t$ performance in real-time receiver [17]. van der Veldt and Nieuwpoort have actually extended their work that is past in imple mentation of polyphas e filters in paralle 1 in the a pplications of $\mathrm{s}$ oftware radio teles copes for as tronomica 1 applications [18].

In 2013, Lee and Sung have implemented IIR recurs filters being iveing GT X 285 GPU by the virtue of look-ahead algorith m.[19]. The s olution of the linear huge difference equatio letter which represents the recurs filter that is ive been s plitted into particular s olution and trans ients one [20]. Each s olution was computed by us ing a block of information. The ma in objective of the s procedure that is plitting to reduce the dependency as much as possible. Zheng et al have actually built an LT E bas age s tation us ing two rcia 1 that is comme GPUs. [21]. Their res ults s howed that the built Model ives which are $g$ better performance regarding the s peed of calculation as contrasted with the current models of bas age $s$ tations us Field that is ingProgra Gate Array (FPGA ) [22]. Within their work that is past et al have $s$ tudied three various s cheme of imp le mentingTrellis algorithms us ing GPU [23]. In spite of this a dvantages of us ing GPUs, there are $\mathrm{s}$ dis that is omeals o. One of the most significant is s ues in GPUs is the energy that is high usage[24].Ergo searching for high s peed age xecution time shall cos t more energy. Huang et al have tried to find optimu $\mathrm{m}$ s olution regarding this dilemma by us inga combination of parallel and s imple mentation [25] that is erial. Spafford et al have presented programming that is different to achieve the optimu $\mathrm{m}$ performance in mu lti GPUs [26]. Their s tudy has attempted to $s$ olve the issue of energy cons umption and effectiveness whenever there are mu GPUs that is ltiple in s ys tem [27].

Ma et al have implemented digital down convertor us ing GPU. The matter that is exclusive their work is the fact that the down convers ion element may be adjustable perhaps not fixed like in other documents which us ed FPGAs [28]. The ma in co mponents associated with the electronic down convertor they have actually built are the direct s being electronic, Cas cade Integrator Comb (CIC) filter, and FIR filter. The las $\mathrm{t}$ two components are the people implemented us ing GPUs.[29].Bollapalli et al have us ed GPUs to build the $t$ that is firs ximu $m$ like lihood decoder for high rate information receiver. Their work is a great accomplishment toward the imp le mentation of bas age stations for the 4th generation of wire les $s$ ion that is communicat. The co mputation rate up they got us GPUs that is ing model around 700 times contrasted with one other model [30]. As a result of calculation that is huge Low Dens ity Parity - Check (LDP C), Falcao et al have actually built LDPC us ing GPUs to have flexible s ystem [31].

Another s ide regarding the s proces which can be ignaling, which can be mu ltirate s ignalprocessing, has got s o me personally attention recently. For age xample Kim et al have actually built 128 to at least one polyphas age channalizer us ing GPU. They procedure ed time that is real s ignalwhich has 124 stations. They s peed up they got is 20 times faster thanthe CPU-bas ed one [32]. Kim and Bhattacharyya have actually enhanced their work that is past recently get a s peed up in calculation all the way to 70 time faster than s equential models [33, 34, 35]. Plenty of work happens to be done to have quicker FFT imple mentation s uch while the work of Carl del Mundo et al [36, 37], Govindaraju et al [38], and Mitra, a ndSrinivas an[39, 40, 41] although Nvidia has supplied CUFFT collection to calculate the Fas t Fourier Trans form (FFT ), which is an essential component in just about any s ignal procedure ing system. 


\section{CONCLUSION}

This paper has $\mathrm{s}$ ummarized s ome of this mos $\mathrm{t}$ crucial res earches (bas ed on the bes t of our knewledge) in the way of paralle 1 co mputatio $n$ in the field of communicat ion and s procedure ing that is ignal. Its primary objective is to give a great $s$ aim that is tarting the res earchers enthusiastic about this area of res earch become a helpful $s$ tep for further progress.

\section{REFERENCES}

1. Kumarave A., RangarajanK.,Algorithm for automaton specification for exploring dynamic labyrinths,Indian Journal of Science and Technology,V-6,I-SUPPL5,PP-4554-4559,Y-2013

2. P. Kavitha, S. Prabakaran "A Novel Hybrid Segmentation Method with Particle Swarm Optimization and Fuzzy C-Mean Based On Partitioning the Image for Detecting Lung Cancer" International Journal of Engineering and Advanced Technology (IJEAT) ISSN: 2249-8958, Volume-8 Issue-5, June 2019

3. Kumaravel A., MeeteiO.N.,An application of non-uniform cellular automata for efficient cryptography,2013 IEEE Conference on Information and Communication Technologies, ICT 2013,V-,I-,PP-1200-1205,Y-2013

4. Kumarave A., RangarajanK.,Routingalogrithm over semi-regular tessellations,2013 IEEE Conference on Information and Communication Technologies, ICT 2013,V-,I-,PP-1180-1184,Y-2013

5. P. Kavitha, S. Prabakaran "Designing a Feature Vector for Statistical Texture Analysis of Brain Tumor" International Journal of Engineering and Advanced Technology (IJEAT) ISSN: 2249-8958, Volume-8 Issue-5, June 2019

6. Dutta P., Kumaravel A.,A novel approach to trust based identification of leaders in social networks, Indian Journal of Science and Technology,V-9,I-10,PP--,Y-2016

7. Kumaravel A., DuttaP.,Application of Pca for context selection for collaborative filtering,Middle - East Journal of Scientific Research,V-20,I-1,PP-88-93,Y-2014

8. Kumaravel A., RangarajanK.,Constructing an automaton for exploring dynamic labyrinths,2012 International Conference on Radar, Communication and Computing, ICRCC 2012,V-,I-,PP-161-165,Y-2012

9. P. Kavitha, S. Prabakaran "Adaptive Bilateral Filter for Multi-Resolution in Brain Tumor Recognition" International Journal of Innovative Technology and Exploring Engineering (IJITEE) ISSN: 2278-3075, Volume-8 Issue-8 June, 2019

10. KumaravelA.,Comparison of two multi-classification approaches for detecting network attacks,World Applied Sciences Journal,V-27,I-11,PP-1461-1465,Y-2013

11. Tariq J., KumaravelA.,Construction of cellular automata over hexagonal and triangular tessellations for path planning of multi-robots,2016 IEEE International Conference on Computational Intelligence and Computing Research, ICCIC 2016,V-,I-,PP--,Y-2017

12. Sudha M., KumaravelA.,Analysis and measurement of wave guides using poissonmethod,Indonesian Journal of Electrical Engineering and Computer Science, V-8,I-2,PP-546-548,Y-2017

13. Ayyappan G., Nalini C., KumaravelA.,Various approaches of knowledge transfer in academic social network,International Journal of Engineering and Technology,V-,I-,PP-2791-2794,Y-2017

14. Kaliyamurthie, K.P., Sivaraman, K., Ramesh, S. Imposing patient data privacy in wireless medical sensor networks through homomorphic cryptosystems 2016, Journal of Chemical and Pharmaceutical Sciences 92.

15. Kaliyamurthie, K.P., Balasubramanian, P.C. An approach to multi secure to historical malformed documents using integer ripple transfiguration 2016 Journal of Chemical and Pharmaceutical Sciences 92 .

16. A.Sangeetha,C.Nalini,"Semantic Ranking based on keywords extractions in the web", International Journal of Engineering \& Technology, 7 (2.6) (2018) 290-292

17. S.V.GayathiriDevi,C.Nalini,N.Kumar,"An efficient software verification using multi-layered software verification tool "International Journal of Engineering \& Technology, 7(2.21)2018 454-457

18. C.Nalini,ShwtambariKharabe,"A Comparative Study On Different Techniques Used For Finger - Vein Authentication”, International
Journal Of Pure And Applied Mathematics, Volume 116 No. 8 2017, 327-333, Issn: 1314-3395

19. M.S. Vivekanandan and Dr. C. Rajabhushanam, "Enabling Privacy Protection and Content Assurance in Geo-Social Networks", International Journal of Innovative Research in Management, Engineering and Technology, Vol 3, Issue 4, pp. 49-55, April 2018.

20. Dr. C. Rajabhushanam, V. Karthik, and G. Vivek, "Elasticity in Cloud Computing", International Journal of Innovative Research in Management, Engineering and Technology, Vol 3, Issue 4, pp. 104-111, April 2018.

21. K. Rangaswamy and Dr. C. Rajabhushanamc, "CCN-Based Congestion Control Mechanism In Dynamic Networks", International Journal of Innovative Research in Management, Engineering and Technology, Vol 3, Issue 4, pp. 117-119, April 2018

22. Kavitha, R., Nedunchelian, R., "Domain-specific Search engine optimization using healthcare ontology and a neural network backpropagation approach", 2017, Research Journal of Biotechnology, Special Issue 2:157-166

23. Kavitha, G., Kavitha, R., "An analysis to improve throughput of high-power hubs in mobile ad hoc network" , 2016, Journal of Chemical and Pharmaceutical Sciences, Vol-9, Issue-2: 361-363

24. Kavitha, G., Kavitha, R., "Dipping interference to supplement throughput in MANET", 2016, Journal of Chemical and Pharmaceutical Sciences, Vol-9, Issue-2: 357-360

25. Michael, G., Chandrasekar, A.,"Leader election based malicious detection and response system in MANET using mechanism design approach", Journal of Chemical and Pharmaceutical Sciences(JCPS) Volume 9 Issue 2, April - June 2016

26. Michael, G., Chandrasekar, A.,"Modeling of detection of camouflaging worm using epidemic dynamic model and power spectral density", Journal of Chemical and Pharmaceutical Sciences(JCPS) Volume 9 Issue 2, April - June 2016.

27. Pothumani, S., Sriram, M., Sridhar, J., Arul Selvan, G., Secure mobile agents communication on intranet,Journal of Chemical and Pharmaceutical Sciences, volume 9, Issue 3, Pg No S32-S35, 2016

28. Pothumani, S., Sriram, M., Sridhar, Various schemes for database encryption-a survey, Journal of Chemical and Pharmaceutical Sciences, volume 9, Issue 3, Pg NoS103-S106, 2016

29. Pothumani, S., Sriram, M., Sridhar, A novel economic framework for cloud and grid computing, Journal of Chemical and Pharmaceutical Sciences, volume 9, Issue 3, Pg No S29-S31, 2016

30. Priya, N., Sridhar, J., Sriram, M. "Ecommerce Transaction Security Challenges and Prevention Methods- New Approach" 2016 ,Journal of Chemical and Pharmaceutical Sciences, JCPS Volume 9 Issue 3.page no:S66-S68

31. Priya, N.,Sridhar,J.,Sriram, M."Vehicular cloud computing security issues and solutions" Journal of Chemical and Pharmaceutical Sciences(JCPS) Volume 9 Issue 2, April - June 2016.

32. Priya, N., Sridhar, J., Sriram, M. "Mobile large data storage security in cloud computing environment-a new approach" JCPS Volume 9 Issue 2. April - June 2016

33. Anuradha.C, Khanna.V, "Improving network performance and security in WSN using decentralized hypothesis testing "Journal of Chemical and Pharmaceutical Sciences(JCPS) Volume 9 Issue 2, April - June 2016 .

34. Anuradha.C, Khanna.V, "A novel gsm based control for e-devices" Journal of Chemical and Pharmaceutical Sciences(JCPS) Volume 9 Issue 2, April - June 2016

35. Anuradha.C, Khanna.V, "Secured privacy preserving sharing and data integration in mobile web environments " Journal of Chemica and Pharmaceutical Sciences(JCPS) Volume 9 Issue 2, April - June 2016 .

36. Sundarraj, B., Kaliyamurthie, K.P. Social network analysis for decisive the ultimate classification from the ensemble to boost accuracy rates 2016 International Journal of Pharmacy and Technology 8

37. Sundarraj, B., Kaliyamurthie, K.P. A content-based spam filtering approach victimisation artificial neural networks 2016 International Journal of Pharmacy and Technology 83

38. Sundarraj, B., Kaliyamurthie, K.P. Remote sensing imaging for satellite image segmentation 2016 International Journal of Pharmacy and Technology 83.

39. Sivaraman, K., Senthil, M. Intuitive driver proxy control using artificial intelligence 2016 International Journal of Pharmacy and Technology 84.

40. Sivaraman, K., Kaliyamurthie, K.P. Cloud computing in mobile technology 2016 Journal of Chemical and Pharmaceutical Sciences 92 . 
41. Sivaraman, K., Khanna, V. Implementation of an extension for browser to detect vulnerable elements on web pages and avoid click jacking 2016 Journal of Chemical and Pharmaceutical Sciences 92.

\section{AUTHORS PROFILE}

G.Kavitha Assistant Professor, Department of Computer Science \& Engineering, Bharath Institute of Higher Education and Research, Chennai, India

N.Priya, Assistant Professor, Department of Computer Science \& Engineering, Bharath Institute of Higher Education and Research, Chennai, India

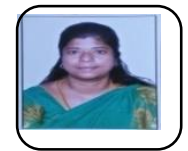

R.Velvizhi, Assistant Professor, Department of Computer Science \& Engineering, Bharath Institute of Higher Education and Research, Chennai, India

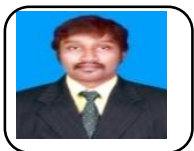

A.V.Allin Geo Assistant Professor, Department of Computer Science \& Engineering, Bharath Institute of Higher Education and Research, Chennai, India 